\title{
SHADE GUIDES USED IN THE DENTAL PRACTICE
}

\author{
Rangel Todorov ${ }^{1}$, BozhidarYordanov ${ }^{1}$, Todor Peev ${ }^{1}$, Stefan Zlatev ${ }^{2}$ \\ 1) Department of Prosthetic Dental medicine, Faculty of Dental medicine, Medical \\ University - Sofia, Bulgaria. \\ 2) Department of Prosthetic Dental medicine, Faculty of Dental medicine, Medical \\ University - Plovdiv, Bulgaria.
}

\section{SUMMARY}

The aim of the article is to present a narrative review of the literature related to the different shade guides available for dental practitioners.

A literature search was performed in the online databases - PubMed, Science Direct, MedLine and GoogleScholar with the following keywords - shade guide, shade matching, dental, dentistry. Furthermore, a hand search, including "grey" literature and printed resources available to the authors, was conducted. More than 2100 unique articles, including the selected keywords, were identified. After a critical review and elimination process, 39 of the papers were included.

Dental shade guides are a set of colour standards mimicking the colour of tissues, which dentists aim to restore - tooth structures, gingival tissues or facial structures in facial prosthodontics - skin, mucosa, eyes etc. They can be systematized based on the following principles - fabrication process, the material of manufacturing or restoration and according to the tissues, which are restored.

The most commonly used shade guides in the dental practice are structured around Munsell's 3-dimensional colour system and are aimed at the restoration of tooth colour. The colour standards for gingival and facial restoration are not routinely utilized since they are aimed at specialists in prosthetic dentistry and facial prosthodontics and are underdeveloped to some degree in comparison with the aforementioned.

The contemporary development in aesthetic restorative materials and procedures requires an adequate follow up in the evolution of shade guides since they present the only means of communication between the dental office and laboratory.

Keywords: shade guide, shade-matching, dental, dentistry, colour,

\section{INTRODUCTION}

Shade guides used in dentistry are comprised of a set of standard or individually fabricated colour standards, which mimic the colour of dental structures [1]. They are used to visually determine a colour match with natural teeth [2 - 4]. Shade guides can be prefabricated or manufactured individually $[5,6]$. Another principle for their classification is based on the material, from which they are made - ce- ramic based, composite resin based or acrylic based. Depending on the structures of interest, shade guides can be divided into groups for tooth or gingival colour matching or the ones used in facial prosthodontics [7 - 10]. The last two are not routinely used in dental practice and are underdeveloped to some degree since their usage is oriented towards more specialized practitioners.

As a general requirement, shade guides for dental structures should represent the full spectrum of colours naturally occurring in the human dentition. They also need to be logically constructed and the tabs ordered in a way that enables easy usage. As a general principle, each shade tab has an incisal, middle and cervical part, which differ based on the colour density and translucency $[11,12]$.

Colour determination is an important point in all directions of prosthetic dentistry $[13,14]$ and the clinical data collected are directed to the dental laboratory at the planning stage of structures $[15,16]$.

\section{MATERIALS AND METHODS}

A literature search was performed in the online databases - PubMed, Science Direct, Medline and Google Scholar with the following keywords - shade guide, shade matching, dental, dentistry. Furthermore, a hand search, including "grey" literature and printed resources available to the authors, was conducted. More than 2100 unique articles, including the selected keywords, were identified. After a critical review and elimination process, 39 of the papers were included.

\section{Development of colour standards}

In 1931 Clark was the first person who attempted to scientifically systematize the colours occurring in the natural dentition. In order to achieve this, he arranged 703 shade tabs, which were divided into two groups representing the gingival or incisal area of the tooth's crown. Those were grouped into 19 degrees for value, 6 for Chroma and 3 for hue, thus the shade guide - "Color Indicator", which consists of 60 shade tabs was created.

Hall creates a shade guide for porcelain restorations, using the principles, which later became the base for the creation of Vita 3D Master. There are shade tabs arranged according to the value in 3 groups - light moderate and dark. Each of those has 9 tabs positioned vertically based on their Chroma and horizontally based on the hue in 3 rows with different tints [17]. 
In 1939 VITA Zahnfabrik created its first shade guide - the result of an epidemiological study for determination of tooth shades occurring in the natural dentition. In 1956 VITA Lumin Vacuum Shade Guide was introduced and marked the first attempt at creating a unified colour standard $[18,19]$. Since then, numerous dental material manufacturers propose different shade guides [20, 21, 22]. These create a bigger diversity but also confuse practising dentists [23, 24, 25, 26].

In 1976-1978 CIE creates a new colour system called CIELab, classifying all the shades mathematically. This enables the easy and accurate definition of different colours using numeric representation. One of the first clinical implications of the system lies in the development of the VITA 3D Master shade guide.

There are 3 main shade guides used in the daily practice, namely the ones developed by VITA, Bioform by De
Trey and Chromascop by Ivoclar. They are based on Munsell's principles, which divide the colour space into three dimensions - name of the colour (hue), the density of the colour (Chroma), and vitality (value) $[8,12]$.

\section{Shade guides manufactured from ceramic materials}

\section{Vita Classical; Vita Lumin}

The colour space in Vita Classical is divided into four groups - A, B, C and D based on the dominating HUE (name of the colour). In group " $A$ " these are red and brown, in group B - red and yellow, in group C - grey and in group D red and grey. Each of the "letter" groups has subdivisions indexed with Arabic numbers ranging from 1 to 4, making the total number of tabs 16. (Fig.1) With the increase of the number, the Chroma increases, while at the same time, the value decreases [27].

Fig. 1. Vita Classical shade guide

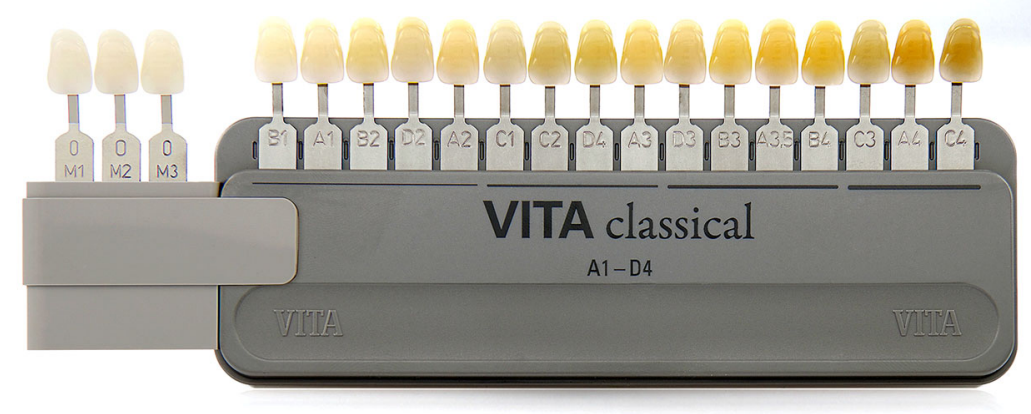

The manufacturer proposes an alternative tab order based on the value, which eliminates the aforementioned structure and creates an arrangement in the following manner: B1, A1, B2, D2, A2, C1, C2, D3, A3, D4, B3, A3.5, B4, $\mathrm{C} 3, \mathrm{~A} 4$, and $\mathrm{C} 4$. In recent years a modification of the shade guide is proposed. Three new tabs for bleached teeth are included - 0M1, 0M2, 0M3 [12].

\section{Vita 3D Master}

This shade guide consists of 26 tabs arranged in 5 groups according to their value. (Fig. 2) Inside the groups, the shade tabs are ordered along two axes - vertical according to Chroma and horizontal based on hue. The first group has two tabs, the second, third and fourth have seven each, while the fifth has three. Each shade tab has three labels - a number ranging from 1 to 5 , showing the group and value level, which decreases as the number increases. The letter $\mathrm{M}$ defines a mean colour tone, which is representative for the given value, while $\mathrm{R}$ and $\mathrm{L}$ are arranged relative to the median colour estimate. The last numeric indicator $-1,1.5$, 2, 2.5 and 3 shows the Chroma levels that are increasing incrementally. Three additional tabs are added for bleached teeth - 0M1, 0M2 and 0M3, the latter denoting the value of 0 , three levels of Chroma and mean colour tone (M) [18].

Fig. 2. Vita 3D Master shade guide

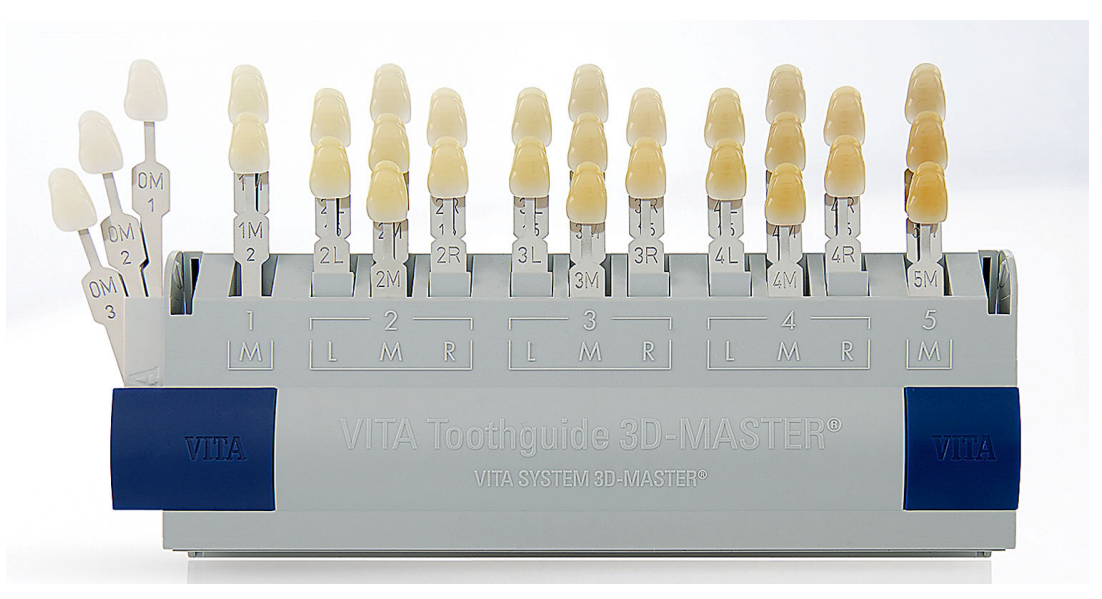


There are several improvements of Vita 3D Master shade guide in comparison to Vita Classical:

- There is a wider value range;

- $\quad$ The red spectra has increased range;

- $\quad$ The shade tabs are more equally distributed in the colour space;

- The group distribution is better and more concise [12].

\section{Vita Linear guide}

In 2006 as a natural development, a new shade guide was proposed - VITA Linearguide. It is based entirely on
3D Master and contains all of its tabs, which are distributed in an innovative manner. Shade tabs are arranged according to their value. The shade guide is further subdivided into six "sub-guides" - one main based on value and five accessories for Chroma and Hue. (Fig. 3) The latter is an attempt to overcome the disadvantages of the previous generations of shade guides. With Vita Classical, shade registration is a one-step process. This presents a difficulty since the correct colour should be chosen among all of the shade guide's tabs. Shade matching with Vita 3D Master is a three-step process, which also leads to difficulties in the correct shade determination [12, 28].

Fig. 3. Vita Linear Guide

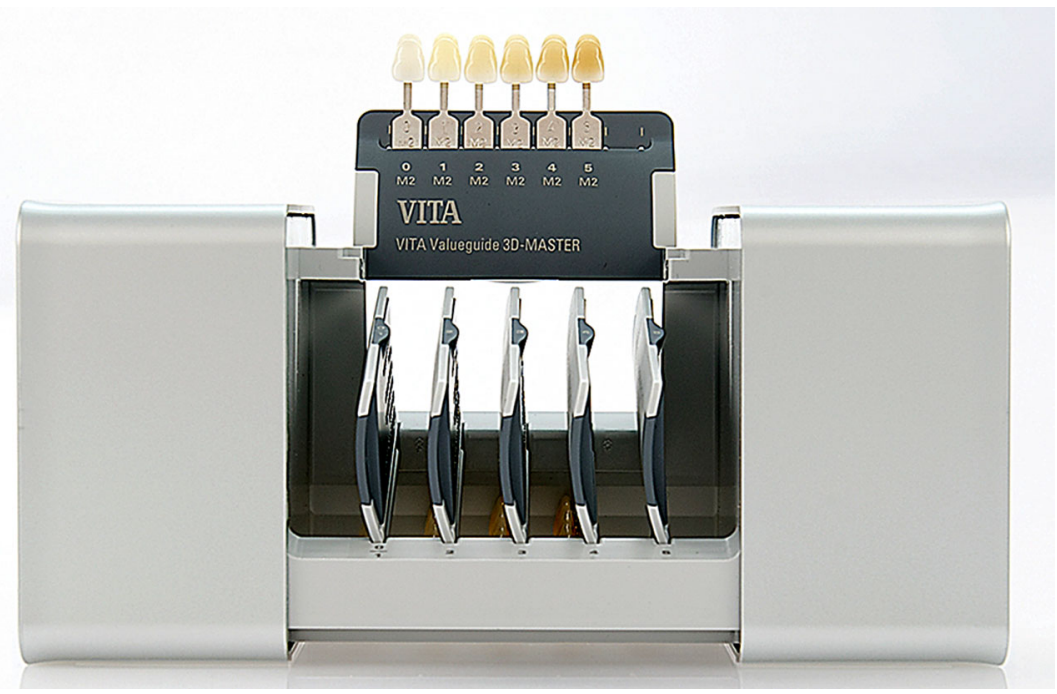

With Vita Linearguide shade registration is a two-step process that is easier and quicker. First, the Value-tab from the main (Value) sub-guide is chosen, followed by the actual (Chroma/Hue) shade tab from one of the accessory subguides. The process is easier and results in a more precise and quicker shade matching since in each stage, the choice is made between a small number of shade tabs [12].

\section{Vita Bleachguide 3D Master}

These colour standards are used for shade matching or evaluation during tooth whitening procedures. The shade guide has 15 tabs which correspond to 29 shades approved by ADA. (Fig. 4) The application of a specialized shade guide aids in the more realistic evaluation of the tooth whitening process, while also contributing to the communication between the dentist and the patient $[4,29,30]$.

Fig. 4. Vita Bleach guide

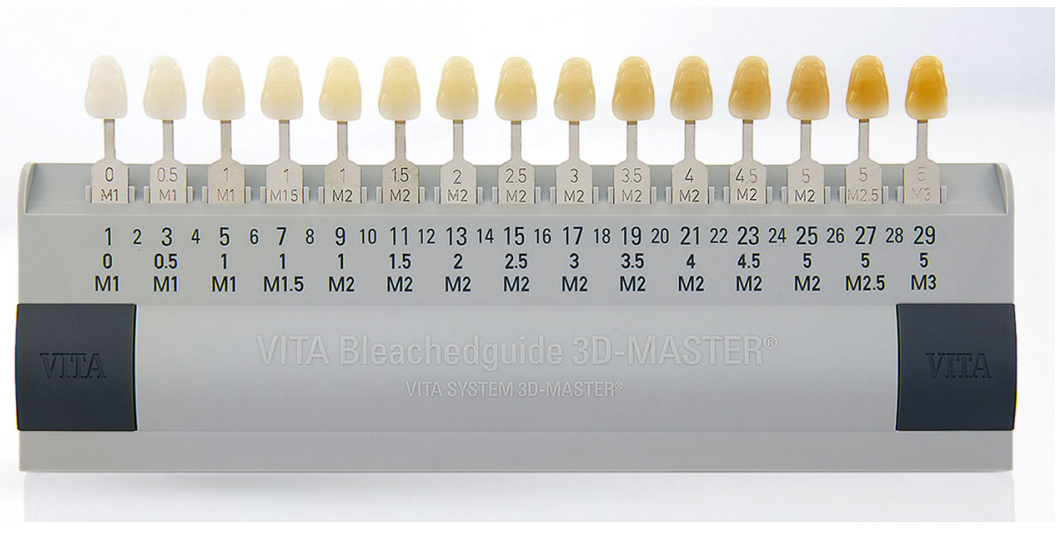


The shade guide follows the logic of tab arrangement used in 3D Master and uses the Value dimension for determining its structure. The numeric indications ranging from 0 to 5 denote the given Value of the shade tab, while the letter indicator, ranging from M1 to M3, and correspond to the Hue dimension similar to the M group in 3D Master [31].

Chromascop (Ivoclar Vivadent, Amherst, NY, USA)

In this shade guide, the colour space is distributed in five groups based on the Hue dimension. The colour-coding is as follows:

$$
\begin{array}{ll}
\text { - } & \text { In group } 100 \text { - white; } \\
\text { - } & \text { In group } 200 \text { - yellow; } \\
\text { - } & \text { In group } 300 \text { - grey; } \\
\text { - } & \text { In group } 400 \text { - grey; } \\
& \text { in group } 500 \text { - dark brown. }
\end{array}
$$

Each group has five shade tabs. With the increase in number the chroma of the colour increases and at the same time the value decreases. The Shade guide consists of 20 tabs. The number for each of them is a combination of he subgroup and the other two colour dimensions. As an addition, accessory shade tabs are added for bleached teeth -010 , 020, 030 and 040 [12].

\section{Bioform}

The overall number of tabs in this shade guide is 24 . The colour space is divided into four groups based on the dominating hue - red-brown, yellow, red-grey and grey [12].

\section{materials}

Shade guides manufactured from composite resin

Most of the manufacturers support the claim that the colour of their composite resin or acrylic materials correspond to the ceramic colour standards [32,33]. Nevertheless almost all of them have specific shade guides supplied with their materials $[12,34]$. The shade tabs made from composite resin materials can be with one or multiple layers depending on the manufacturing process. Sometimes the manufacturers supply "protocols" for mixing of different enamel and dentin masses so that the desired shade can be achieved [35].

The shade tab's order is analogous to the logic used in the ceramic based shade guides. Disinfecting solutions, heat, polishing and storage time can greatly affect composite resin materials and should be taken into consideration when using these shade guides [27, 36].

Among the more widely used shade guides from this group are Esthetic-X, TetricEvo Ceram and Venus.

\section{Esthetic-X (Dentsply)}

This shade guide consists of 16 shade tabs with the addition of a universal, universal-light, light-grey and yellow-grey and three tabs for bleached dental tissues [12].

TetricEvo Ceram (Ivoclar Vivadent)

The shade guide consists of 11 colour standards, 3 dentin colours, one tab for evaluation of translucency and 4 for bleached teeth [12].

\section{Venus (HereusKulzer)}

The colour standards are arranged in three groups 15 standard shade tabs, three for evaluation of translucency and two for bleached structures [12].

\section{Shade guides for soft tissues in the cranial-facial} area

The use of a universal pink shade cannot reproduce the colour characteristics of gingival tissues [10].

The colour space in gingival tissues has a bigger spectre than that for dental structures, where the value and hue have wider borders and the Chroma narrower. The colour of the restoration's base, be it fixed or removable, can be reproduced using a standard or individually manufactured shade guide. With the usage of the later individual characteristics of soft tissues can be highlighted [12].

Most frequently used standard shade guides for soft tissues in dentistry are Lucitone 199, Dentsply Trubute and Ivoclar Plus Gingiva indicator [37].

Alongside the main characteristics of colour - value, hue and Chroma, important aspects of shade matching procedures for soft tissues include the size, shape and thickness of the restorations as well as the ethnic background of the patient.

\section{Shade guides for facial prosthodontics}

The accurate recreation of individual colour characteristics of soft tissues in the facial area requires the usage shade guides developed for facial prostheses. Although the colour range of human skin is wide, there are no universally accepted shade guides for facial prosthodontics [9].

Over proposes a 7 step silicon guide and points out that one of the most important aspects in such restorations is the construction's depth [37]. Godoy develops an acrylic guide consisting of 7 shade tabs [7].

Clinically (individually) fabricated shade guides

It is not always possible to determine the colour match between the natural dentition and commercially available shade guides $[12,26]$. The individually fabricated shade guides have the advantage that they are made from the material which will be used for the final restoration [33]. As an additional advantage, there is the possibility to create several options with variable thickness, surface structure, glaze and individualization of different colour characteristics.

Colour determination is an important factor in satisfying the aesthetic medical-biological indicator of different types of prosthetic treatments in both adult and paediatric patients $[38,39,40]$.

\section{CONCLUSION}

Colour dimensions of dental structures and their reconstruction have its place in achieving a harmonious dentition. Shade guides for soft tissues and facial prosthodontics should be further developed. The accurate recreation of colour dimensions in an important step for achieving a harmonious dentition. The dentist has a plethora of options concerning shade matching for hard tooth substances (i.e. white aesthetics). The development of shade guides follows the logical and technical progress, with its peak - the creation of Vita Linear Guide.

Soft tissue aesthetics (i.e. pink aesthetics) and the recreation of skin colour is still an underdeveloped area with little to none existing shade guides. Further research is needed in order to create a universally accepted and applicable colour standard for these cases. 


\section{REFERENCES:}

1. Clark EB. Tooth color selection. J Am Dent Assoc. 2019 Jun;20(6): 1065-73. [Crossref]

2. Hadjieva H, Dimova M. Visualization of the clinical observations in the different stages of the dental prosthetic treatment process. Pharmacologyonline. 2008 Aug 30;2:99-104. [Internet]

3. Hadjieva H, Dimova M, Peev T. [Clinical procedures contributing to the esthetic result by total denture treatment.] Zabolekarskipregled. 2006; 2:108-12. [in Bulgarian]

4. Joiner A. Tooth colour: a review of the literature. J Dent. 2004; 32(Suppl 1):3-12. [PubMed] [Crossref]

5. Aleksandrov S, Todorov G, Hristov S. [Embellishment of prognostic constructions for precise asthetical planning.] Proceedings of SUBPlovdiv. 2011;14:10-2. [in Bulgarian]

6. Todorov R, Todorov G. [Systems for registration and devices for color measurement.]Proceedings of SUBPlovdiv. 2012; 14:5-9. [in Bulgarian]

7. Godoy AJ, Lemon JC, Nakamura SH, King GE. A shade guide for acrylic resin facial prostheses. J Prosthet Dent. 1992 Jul;68(1):120-2. [PubMed] [Crossref]

8. Pustina-Krasniqi T, Shala K, Staka G, Bicaj T, Ahmedi E, Dula L. Lightness, chroma, and hue distributions in natural teeth measured by a spectrophotometer. Eur J Dent. 2017 Jan-Mar;11(1):36-40. [PubMed] [Crossref]

9. Mehta S, Nandeeshwar DB. A spectrophotometric analysis of extraoral aging conditions on the color stability of maxillofacial silicone. J Indian Prosthodont Soc. 2017 Oct-Nov; 17(4):355-60. [PubMed] [Crossref]

10. Hyun H-K, Kim S, Lee C, Shin TJ, Kim Y-J. Colorimetric distribution of human attached gingiva and alveolar mucosa. J Prosthet Dent. 2017 Feb; 117(2):294-302. [PubMed] [Crossref]

11. Hammad IA. Intrarater repeatability of shade selections with two shade guides. J Prosthet Dent. 2003 Jan;89(1):50-3. [PubMed] [Crossref]

12. Paravina RD. Performance assessment of dental shade guides. $J$ Dent. 2009; 37(Supl 1):e15-20. [PubMed] [Crossref]
13. Hadjieva H, Dimova M, Peev T. Total rehabilitation by edentulous patients with irregularity of the alveolar ridges. $J$ of $I M A B$. 2005; 11(2):54-56. [Internet]

14. Dimova M, Hadjieva H, Peev T. [Oral clinical patient record for observation data of edentulous patients.] Dental medicine. 2009; 1: 34-40. [in Bulgarian]

15. Dimova M, Hadjieva H, Peev T. [Documented data transferand directions between clinicand laboratory in total prosthetics.] Zabolekarski pregled. 2006; 2: 103-107. [in Bulgarian]

16. DimovaM, Jankova M, Peev T. [An inquiry into the laboratory shaping in fabrication of complete dentures.] Problems of dental medicine. 2008; XXXIV(II):43-49. [in Bulgarian]

17. Sproull RC. Color matching in dentistry. part I. The three-dimensional nature of color. J Prosthet Dent. 1973 Apr;29(4):416-24.

[PubMed] [Crossref]

18. Brewer JD, Wee A, Seghi R. Advances in color matching. Dent Clin North Am. 2004 Apr;48(2):341-58. [PubMed]

19. Rao D, Joshi S. Evaluation of Natural Tooth Color Space of the Indian Population and Its Comparison to Manufacturer's Shade Systems. Contemp Clin Dent. 2018 Jul-Sep; 9(3):395-399. [PubMed]

20. Ho DK, Ghinea R, Herrera LJ, Angelov N, Paravina RD. Color Range and Color Distribution of Healthy $\mathrm{Hu}-$ man Gingiva: a Prospective Clinical Study. Sci Rep. 2015 Dec 22;5:18498. [PubMed] [Crossref]

21. Gomez-Polo C, Gomez-Polo M, Martinez Vazquez de Parga JA, CeleminVinuela A. Study of the most frequent natural tooth colors in the Spanish population using spectrophotometry. J Adv Prosthodont. 2015 Dec;7(6):413-22. [PubMed]

22. Paolone G, Orsini G, Manauta J, Devoto W, Putignano A. Composite shade guides and color matching. Int J Esthet Dent. 2014 Summer;9(2): 164-82. [PubMed]

23. Dimova M, Peev T. [Methodical approach for evaluation of the patient satisfaction with prosthetic treat- ment with provisional crowns and bridges. Social medicine. 2003; 1:2930. [in Bulgarian]

24. Dimova M, Peev T. [Satisfaction of patients with prosthetic treatment with laboratory provisional constructions (study results).] Social medicine. 2003;4: 30-32. [in Bulgarian]

25. Dimova M, Peev T. [Method for laboratory determination of the shape of the upper frontal teeth in total prosthetic treatment (a pre-release message).] Scientific Researches of the Union of Scientists in Bulgaria Plovdiv 2007, Series Â. Natural Sciences and the Humanities. 2008; IX: 165-170. [in Bulgarian]

26. Paravina R, Stankovic D, Aleksov L, Mladenovic D, Ristic K. Problems in standard shade matching and reproduction procedure in dentistry: a review of the state of the art. Facta Universitatis, Serbia. 1997; 4(1):12-6.

27. Udiljak Z, Illes D, Knezovic Zlataric D, Celic R. Effect of clinical experience on the shade matching accuracy in different dental occupational groups. Acta Stomatol Croat. 2018 Jun;52(2):132-139. [PubMed]

28. Yuan JC-C, Brewer JD, Monaco EA, Davis EL. Defining a natural tooth color space based on a 3-dimensional shade system. J Prosthet Dent. 2007 Aug;98(2):110-9. [PubMed]

29. Joiner A, Luo W. Tooth colour and whiteness: A review. J Dent. 2017 Dec;67:3-10. [PubMed]

30. MiyajiwalaJS, KheurMG, Patankar AH, LakhaTA. Comparison of photographic and conventional methods for tooth shade selection: A clinical evaluation. J Indian Prosthodont Soc. 2017 Jul-Sep;17(3):273281.[PubMed]

31. Paravina RD, Ontiveros JC, Powers JM. Curing-dependent changes in color and translucency parameter of composite bleach shades. J Esthet Restor Dent. 2002;14(3):158-66. [PubMed]

32. Baratieri LN, Araujo E, Monteiro S, Jr. Color in natural teeth and direct resin composite restorations: essential aspects. Eur J Esthet Dent. 2007 Summer;2(2):172-86. [PubMed] 
33. Ferracane JL. Current trends in dental composites. Crit Rev Oral Biol Med. 1995; 6(4):302-18. [PubMed]

34. Yap AU. Color attributes and accuracy of vita-based manufacturers' shade guides. Oper Dent. 1998 SepOct;23(5):266-71. [PubMed]

35. Ragain JC. Jr, Johnston WM. Color acceptance of direct dental restorative materials by human observers. Color Res Appl. 2000; 25(4):27885. [Crossref]
36. Fay RM, Servos T, Powers JM. Color of restorative materials after staining and bleaching. Oper Dent. 1999 Sep-Oct;24(5):292-6. [PubMed]

37. Over LM, Andres CJ, Moore BK, Goodacre CJ, Munoz CA. Using a colorimeter to develop an intrinsic silicone shade guide for facial prostheses. J Prosthodont. 1998 Dec;7(4):237-49. [PubMed]

38. Dimitrova D. [Fixed prosthetic treatment in childhood - functional aspects.] [dissertation]. Medical University - Varna. 2018. 189 p. [in Bulgarian]

39. Dimitrova D. Questionnaire survey of removable prosthetic treatment in children. MedInform. 2019; 6(1):980- 986. [Crossref]

40. Dimitrova D. Study of patient satisfaction with prosthetic treatment. MedInform. 2018; 5(3):914-919. [Crossref]

Please cite this article as: Todorov R, Yordanov B, Peev T, Zlatev S. Shade guides used in the dental practice. $J$ of IMAB. 2020 Apr-Jun;26(2):3168-3173. DOI: https://doi.org/10.5272/jimab.2020262.3168

Received: 29/06/2019; Published online: 01/06/2020

Address for correspondence:

Rangel Todorov

Faculty of dental medicine, MU-Sofia

1, G. Sofijski Str.,1431 Sofia, Bulgaria.

E-mail: rangeto@gmail.com, 